\title{
Bacteria-Resist Finish on Cotton Fabric Using Natural Herbal Extract
}

\author{
Puspa*, V. Singh and * P. Punia * \\ Department of Textile \& Apparel Designing, COHS, \\ CCS Haryana Agricultural University, Hisar 125 004, Haryana, India \\ *Corresponding author
}

\section{Keywords}

Pseudomonas, Chloroxylenol, Viscous, Antiseptic, Soxhlet method.

\section{Article Info}

Accepted:

05 February 2020

Available Online:

10 March 2020

\section{A B S T R A C T}

Bacteria grow very rapidly under warmth and moisture. Many plant extracts from roots, stem, leaves, flowers, fruits and seeds of diverse species of plants exhibit anti-bacterial properties. These can be used for treating the textiles and the relatively lower incidence of the adverse reaction of these treatments coupled with reduced cost can be exploited as an effective eco-friendly alternative to the synthetic antimicrobial agents for textile applications. Utilization of karanja leaves which are available in abundance and underutilized may be found effective for treatment of resistance against micro-orgasms on cotton fabric. Karanja extract have been used to impart the bacterial resistant property on cotton fabric. Karanja methanolic extract from leaves in viscous and dry state were prepared by soxhlet method and impregnated in $2.5 \mathrm{~g} / \mathrm{l}$ concentration. The antiseptic containing chloroxylenol treatment was taken as standard. The effect of all karanja extract treatments and antiseptic containing chloroxylenol (standard) treatment, were tested for Pseudomonas bacteria resistance activity, quantitatively by AATCC-100 test method. Bacteria count of treated samples again tested and determined percent reduction. It was concluded that leaves extracts in viscous state were more effective than other treatments and it was found hundred percent reductions effective after 30 minutes of inoculation of Pseudomonas bacteria. However, it is leaves extracts in viscous state showed comparable results with the antiseptic containing chloroxylenol (standard). In some cases leaves extracts in viscous state was even more effective than antiseptic treatment.

\section{Introduction}

Microbes are the tiniest creatures which cannot be seen with the naked eye and can be found almost everywhere in the environment. For the growth and multiplication of microorganisms, the minimum nutritional requirements are water, a source of carbon, nitrogen and some inorganic salts. Microorganisms include a variety of organisms like bacteria, fungi, algae and viruses. Bacteria grow very rapidly under warmth and moisture.

Some specific types of bacteria are pathogenic and cause cross infection as these are capable of invading the body of a human, where they replicate and cause tissue damage. They can act as the carriers of some microorganisms such as pathogenic bacteria, odour generating bacteria and mould 2 fungi. Pathogenic micro-organisms like 
Pseudomonas aeuroginosa, Staphylococcus epidermidis, Staphylococcus aureus and Candida albicans have been found on textiles. They damage the textile substrate and also may promote skin contamination and inflammation in sensitive people (Haug et al., 2006). Microbes may also cause a decrease in fabric mechanical strength (Gao \& Cranston, 2008).Therefore, there is a need to inhibit the microbial growth on textile substrate.

Bacterial growth on the textiles can be inhibited by applying chemical and natural botanical anti-microbial agents. These may kill (biocidal) the micro-organisms by damaging the cell wall (Madigan et al., 2006), destroy the growth of micro-organisms and their negative effects of odour, staining and deterioration. In recent years, anti-microbial agents like triclosan, quaternary ammonium compounds, metal salts solutions, antibiotics and nanosilver are available for use on textiles (Mahesh et al., 2011). Synthetic antimicrobial agents leads to fabric strength loss, make the fabric stiff, change the colour of the fabric and also harmful for the environment (Hussain, 2006).To overcome the problems herbal treatments can be given to control the microbial growth on textiles.

Many plant extracts from roots, stem, leaves, flowers, fruits and seeds of diverse species of plants exhibit anti-bacterial properties. These can be used for treating the textiles and the relatively lower incidence of the adverse reaction of these treatments coupled with reduced cost can be exploited as an effective eco-friendly alternative to the synthetic antimicrobial agents for textile applications. Due to the myriad of potential benefits they possess, plants have been widely exploited in traditional medicine and their curative potentials are well 3 documented (krishnaiah et al., 2009). People belief that green medicine is safe and dependable, compared with costly synthetic drugs that have adverse effects (Satish et al., 2008). Utilization of karanja leaves which is available in abundance and underutilized may be found effective for treatment of resistance against micro-orgasms on cotton fabric (Bakhru, 2001). In present work, karanja leaves extract have been used to impart the bacterial resistant property on cotton fabric.

\section{Materials and Methods}

\section{Material used}

Hundred \% cotton (scoured) fabric and -an antiseptic containing chloroxylenol were procured from local market of Hisar city. Leaves of Karanja plant were collected from different places in campus CCS HAU Hisar. Pseudomonas bacteria were also readily available in the department of Microbiology, College of Basic Sciences and Humanities, CCS HAU, Hisar.

\section{Pre-treatment of fabric}

Cotton fabric was desized in a solution containing $1 \% \mathrm{H}_{2} \mathrm{SO}_{4}$ at $50^{\circ} \mathrm{C}$ for 60 minutes with material to liquor ratio $1: 40$. The fabric was rinsed thoroughly to remove any starch and acid residues. The fabric was weighed, soaked, squeezed, and treated in a solution containing 1 percent soap, 3 percent soda ash and 0.5 percent sodium sulphite at boiling temperature $\left(100^{\circ} \mathrm{C}\right)$ with $1: 40$ material to liquor ratio for 60 minutes. After that the fabric was rinsed thoroughly and dried on a flat surface (Gaba, 1999). Sample taken from scoured cotton was kept as control sample.

\section{Preparation of karanja Leaves Extract}

Extraction was carried out by refluxing (soxhlet) and distillation methods. Leaves extract in viscous state and leaves extract in dry state of Karanja plant were prepared. Through silica gel viscous extracts were converted in dry state. 


\section{Application of karanja Leaves extracts on} cotton fabric

Solution of karanja extracts of leaves in viscous and dry state in $2.5 \mathrm{~g} / \mathrm{l}$ concentrations was prepared. The concentration of $2.5 \mathrm{~g} / \mathrm{l}$ for treatments were selected on the basis of review. On the basis of weight of the fabric quantity 1:20 material to liquor ratio of karanja leaves extract were calculated. Four pieces of scoured cotton fabric were sterilized and impregnated with these four prepared solutions separately. The samples were immersed in the treatment bath for 30 minutes. Without squeezing the fabric was placed in the dry place.

Preparation and application of an antiseptic containing chloroxylenol on cotton fabric

Solution of an antiseptic containing chloroxylenol was prepared in distilled water in $2.5 \mathrm{~g} / \mathrm{l}$ concentration. Material to liquor ratio was taken as 1:20. Another piece of cotton fabric was sterilized and immersed in the solution for 30 minutes. Without squeezing the fabric was kept overnight for drying. The antiseptic treatment was taken as standard.

\section{Determination of microbial population on controlled and treated fabrics by quantitatively AATCC-100 test method}

The microbial population (total colony forming units) of treated samples without and with inoculation of Pseudomonas was determined quantitatively using AATCC-100 test method. The size of sample for determination of Pseudomonas population was $2 " \times 2$ " inches were taken from karanja extract treated cotton fabric samples. To assess the bacterial count and percent reduction of treated and untreated samples, the sample was dipped in PDA (Potato
Dextrose Agar) medium sterilized water overnight in a petri dish. Serial dilution $\left(10^{-1}\right.$, $10^{-2} 10^{-3}, 10^{-4}$ and $10^{-5}$ ) was carried out to bacterial count. From each of prepared dilutions, $0.1 \mathrm{ml}$ was transferred onto the prepared petri dish and spread with the help of spreader under laminar flow. The work was done in duplicates. The petri dishes were placed in the incubator set as $30^{\circ} \mathrm{C}$ for 24 hours for the growth of bacteria. The colonies of bacteria were counted manually and \% reduction was also calculated.

Samples treated with leaves extract in viscous state (LEVS), solution of dry leaves power (SDLP) and solution of antiseptic containing chloroxylenol (standard) without inoculation of Pseudomonas were kept as control samples for determining the bacteria growth and population against inoculated samples. These were named as $\mathrm{C}_{1}, \mathrm{C}_{2}, \mathrm{C}_{3}, \mathrm{C}_{4}$ and $\mathrm{C}_{5}$ respectively.

\section{Results and Discussion}

\section{Assessment of efficacy of karanja extracts with $2.5 \mathrm{~g} / \mathrm{l}$ concentration at different intervals on Pseudomonas inoculated samples}

To study the effect of treatment on treated samples, the Pseudomonas growth was counted quantitatively by AATCC-I00 test method. The effect of leaves extracts in viscous and dry state after inoculation on samples (treated samples) was compared with samples treated with antiseptic containing chloroxylenol (standard) samples. These samples were inoculated with Pseudomonas separately. The observations were recorded after 30 min. of inoculation of Pseudomonas on the same day. The observations were also recorded at time intervals of $7^{\text {th }}, 14^{\text {th }}$ and $21^{\text {st }}$ days with dilution factors $10^{-4}$ and $10^{-5}$ mean. Mean values of $10^{-4}$ and $10^{-5}$ dilution factors were calculated. 
The data in Table-1 and Fig.-1 indicated assessment of efficacy of treatments with 2.5 $\mathrm{g} / \mathrm{l}$ concentration of leaves extracts in viscous and dry states at different intervals on Pseudomonas inoculated samples. The percent reduction was compared with the both control samples i.e. scoured untreated sample and samples treated with leaves extracts both in viscous and dry state and without any bacterium inoculation $\left(\mathrm{C}_{1}-\mathrm{C}_{5}\right)$.

Colony forming units were not present on control samples after 30 minutes, $7^{\text {th }}, 14^{\text {th }}$ and $21^{\text {st }}$ days of inoculation in both dilution factors $10^{-4}$ and $10^{-5}$. There was confluent growth on control, untreated samples after 30 minutes, $7^{\text {th }}, 14^{\text {th }}$ and $21^{\text {st }}$ days of inoculation with both dilution factors $10^{-4}$ and $10^{-5}$.

There was 100 percent reduction in Pseudomonas growth after $30 \mathrm{~min}$. of inoculation in leaves extract in viscous and dry state and antiseptic containing chloroxylenol (standard) treated samples in both dilution factors. On $7^{\text {th }}$ day $99.75,99.7$, $99.15,98.65 \& 99.65$ percent reduction in Pseudomonas growth was found on samples treated with leaves extract in viscous state (LEVS), solution of dry leaves powder (SDLP) and antiseptic containing chloroxylenol (standard) with mean CFUs $10^{-}$ ${ }^{4}$ and $10^{-5}$ in dilution factors respectively.

Percent reduction in Pseudomonas growth in LEVS was higher than solution of dry leaves powder and antiseptic (standard) treated sample. There were $98.75,97.55 \& 98.2$ percent reduction in Pseudomonas growth on 14th day on samples treated with leaves extract in viscous state, solution of dry leaves powder and antiseptic containing chloroxylenol (standard) treated samples with mean CFUs in $10^{-4}$ and $10^{-5}$ dilution factors respectively. Percent reduction in Pseudomonas growth in LEVS was higher than SDLP and antiseptic (standard) treated sample.

Table.1 Assessment of efficacy of karanja extracts at different intervals on Pseudomonas inoculated samples

\begin{tabular}{|c|c|c|c|c|}
\hline \multirow[t]{2}{*}{ Incubation } & After $30 \mathrm{~min}$. & 7 Days & 14 Days & 21 Days \\
\hline & Pseudomonas & Pseudomonas & Pseudomonas & Pseudomonas \\
\hline $\begin{array}{c}\text { Dilution } \\
\text { Treatments }\end{array}$ & $\begin{array}{l}10^{4} \& 10^{5} \\
\text { Mean }\end{array}$ & $\begin{array}{c}10^{4} \& 10^{5} \\
\text { Mean }\end{array}$ & $\begin{array}{c}10^{4} \& 10^{5} \\
\text { Mean }\end{array}$ & $\begin{array}{l}10^{4} \& 10^{5} \\
\text { Mean }\end{array}$ \\
\hline $\begin{array}{c}\text { Leaves Extract in Viscous state } \\
\text { (LEVS) }\end{array}$ & 100 & 99.75 & 98.75 & 98.00 \\
\hline $\begin{array}{l}\text { Solution of Dry Leaves Powder } \\
\text { (SDLP) }\end{array}$ & 100 & 99.15 & 97.55 & 97.35 \\
\hline Chloroxylenol (Standard) & 100 & 99.65 & 98.2 & 97.95 \\
\hline Control (C) & & Conflue & t Growth & \\
\hline $\begin{array}{l}\text { Without Bacteria inoculation }\left(\mathbf{C}_{1^{-}}\right. \\
\left.\mathbf{C}_{5}\right)\end{array}$ & & & & \\
\hline
\end{tabular}

*Concentration $2.5 \mathrm{~g} / \mathrm{l}$ 


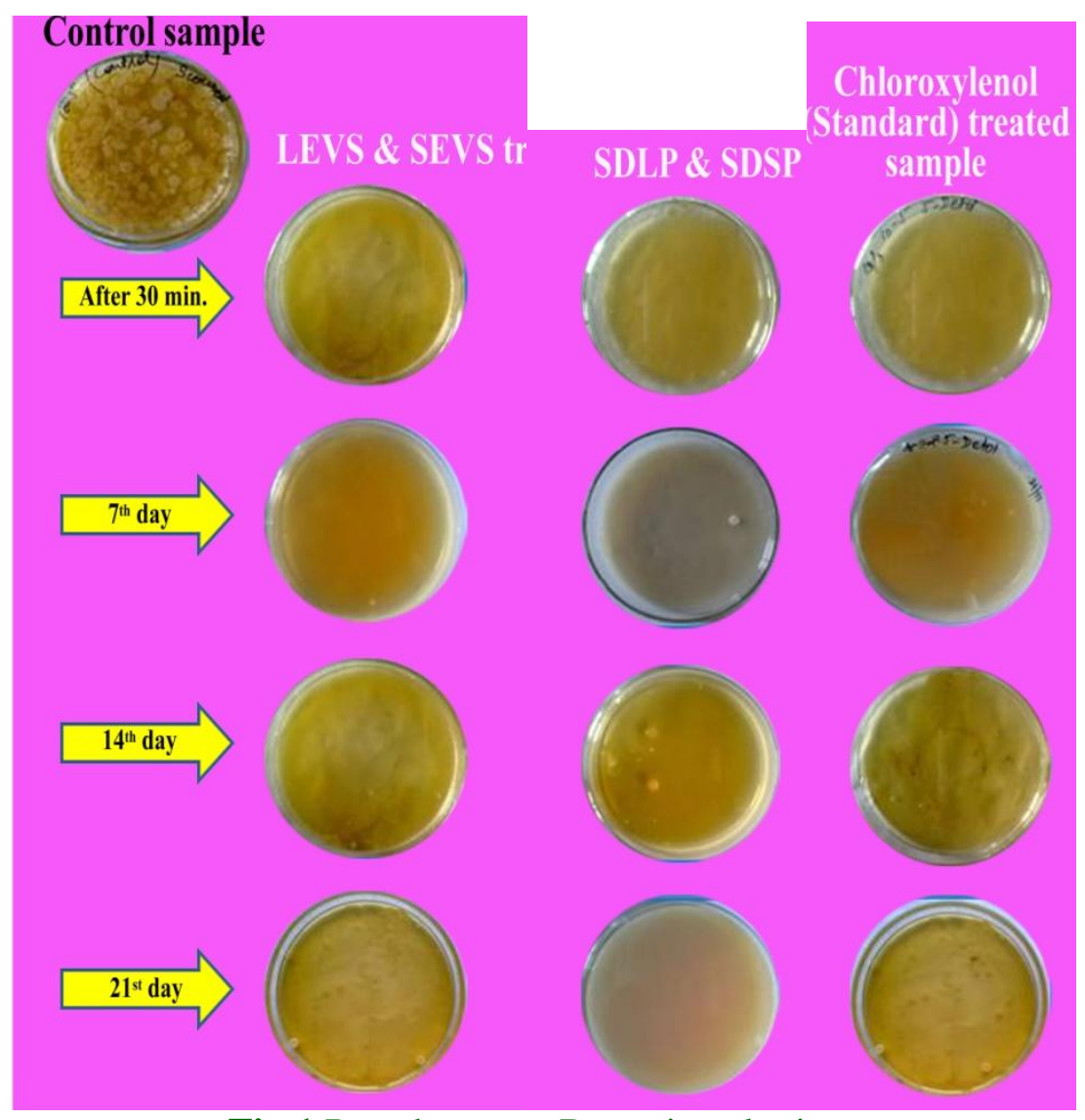

Fig.1 Pseudomonas Bacteria colonies

On 21st day 98.00, $97.35 \& 97.95$ percent reduction in Pseudomonas growth on samples treated with leaves extract in viscous state and solution of dry leaves powder and antiseptic containing chloroxylenol (standard) treated samples was observed with mean CFUs in $10^{-4}$ and $10^{-5}$ dilution factors respectively. Percent reduction in Pseudomonas growth in LEVS was higher than antiseptic (standard) treated sample. On comparing the samples treated with leaves extract in viscous and dry state in $2.5 \mathrm{~g} / \mathrm{l}$ concentration the treatment with leaves extract in viscous state was found more effective as compared to treatments with solution of dry leaves powder. When treatment of samples in leaves extract in viscous state and dry state were compared leaves extract treatment was found more effective than leaves extract in dry state treatment. On comparing the efficacy of all treated samples among themselves and with antiseptic containing chloroxylenol (standard) treated sample, treatment with leaves extract in viscous state showed the best efficacy. Thus, it is concluded that treatment with leaves extracts in viscous state was the most effective among solution of dry leaves powder treatments even as compared to antiseptic treatment- taken as standard. There was subsequent reduction in percent reduction with increase in time period.

It was concluded that leaves extracts in viscous state was more effective than solution of dry leaves treated samples. Leaves extracts in viscous state showed comparable results with the antiseptic containing chloroxylenol (standard). In some cases leaves extracts in viscous state was more effective than antiseptic treatment. 


\section{References}

Gaba, G. 1999. Application of floral dyes on cotton fabric. Unpublished M.Sc. Thesis, CCS Haryana Agricultural University, Hisar.

Katole, S.R., Thakare, H.S. and Mahajan, R.K. 1993. Effect of some plant products and insecticides on the infestation of citrus leaf miner on Nagpur mandarin. J. Maharashtra Agri. Univ., 18(1):67-68.
Malpani, S.R. 2013. Antibacterium treatment on cotton fabric from neem oil, alov vera \& tulsi. International Journal of advance Research in Science and Engineering. 2(7):35-43.

Senti, G., Rolla, A., Schmid-Grendelmeier, P., Johansem, P., Wuthrich, B., and Haug, S., 2006.Coated textiles in the treatment of atopic dermatitis. Skin and Biofunctional Textiles - Currents Problems of Dermatology.33: 144-151.

\section{How to cite this article:}

Puspa, V. Singh and P. Punia. 2020. Bacteria-Resist Finish on Cotton Fabric Using Natural Herbal Extract. Int.J.Curr.Microbiol.App.Sci. 9(03): 229-234.

doi: https://doi.org/10.20546/ijcmas.2020.903.027 